\title{
A climate perspective of the quasi-stationary front in southwestern China: structure, variation and impact
}

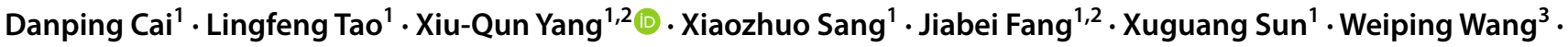 \\ Hongming Yan ${ }^{4}$
}

Received: 5 September 2021 / Accepted: 6 January 2022 / Published online: 25 January 2022

(c) The Author(s) 2022

\begin{abstract}
Yunnan-Guizhou quasi-stationary front (YGQSF) is a unique weather phenomenon that frequently occurs during the winter half year over the Yunnan-Guizhou Plateau in southwestern China. Most of the previous studies analyzed it only with synoptic cases. This study investigates the structure, variation, and impact of this front from a climate perspective, using long-term high-resolution atmospheric reanalyses and high-density station records for 1981-2016. An objective method quantifying YGQSF is proposed and three indexes are defined to measure its intensity, frequency, and location, respectively, with horizontal gradient of air potential temperature at a terrain-following level of sigma 0.995. With these indexes, climatological structure, subseasonal variability as well as climatic impact of the front are comprehensively examined. In climatology, YGQSF as a north-south-oriented low-level front is found to occur the most frequently during January-February-March, determined predominately by the coldness from the east of the front. The structure of the front identified essentially reflects an obstruction of high-terrain Yunnan (the western part of the plateau) to the low-level cold air mass, which makes near-surface cold northeasterly winds cease westward intruding and veer upward over relatively low-terrain Guizhou, transporting moisture upward and forming low clouds. A sharp climate contrast is thus formed between two sides of the front: cold, sunless, and continuously rainy Guizhou versus warm and sunny Yunnan. Furthermore, the front features significant subseasonal variations with periods at around 30 days and 60 days largely in its intensity. Anomalously strong YGQSF events which are caused $75 \%$ by the cold anomaly from the east but no more than $17 \%$ by the warm anomaly from the west yield different anomalous structures, but consistently amplify the sharp climate contrast between Yunnan and Guizhou.
\end{abstract}

Keywords Quasi-stationary front · Cloud and rainfall · Subseasonal variation · Yunnan-Guizhou Plateau · Southwestern China

\section{Introduction}

Lingfeng Tao

Iftao@nju.edu.cn

Xiu-Qun Yang

xqyang@nju.edu.cn

1 CMA-NJU Joint Laboratory for Climate Prediction Studies, School of Atmospheric Sciences, Nanjing University, Nanjing 210023, China

2 Southern Marine Science and Engineering Guangdong Laboratory (Zhuhai), Zhuhai 519082, China

3 Guizhou Climate Center, Meteorological Bureau of Guizhou Province, Guiyang 550002, China

4 Yunnan Climate Center, Meteorological Bureau of Yunnan Province, Kunming 650034, China
The quasi-stationary front is a unique weather phenomenon that frequently occurs during the winter half year in southwestern China. Since this front is found to be always anchored in the Yunnan-Guizhou Plateau, a specific region with the Tibetan Plateau on its northwestern side and vast plains and hills on its eastern side (Fig. 1), it is usually referred to as the Yunnan-Guizhou quasi-stationary front (YGQSF). The topographic altitude of the Yunnan-Guizhou Plateau is $2 \sim 4 \mathrm{~km}$, and the topography of Yunnan Province (the western part of Yunnan-Guizhou Plateau) is generally $1 \mathrm{~km}$ higher than that of Guizhou Province (the eastern part of Yunnan-Guizhou Plateau). When a cold air mass moving from the eastern plains and hills to the Yunnan-Guizhou Plateau meets a warm air mass moving from the western 
topographic altitude

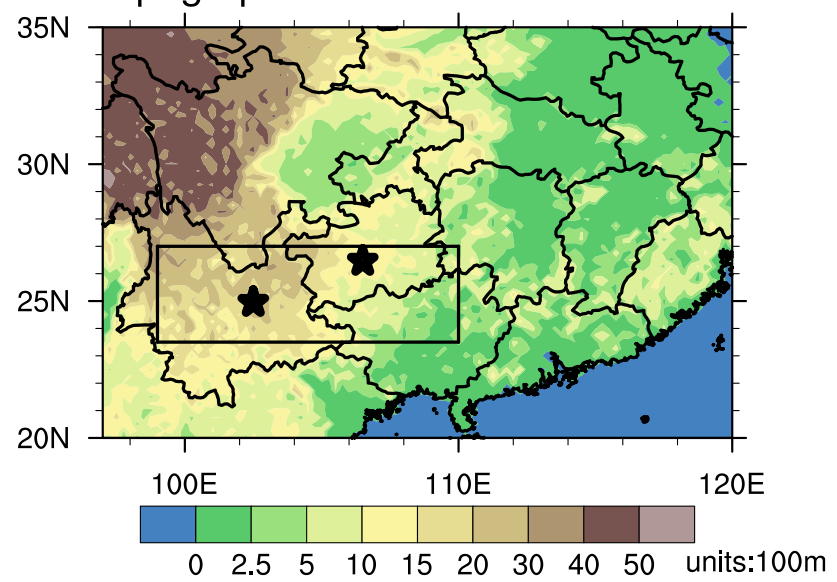

Fig. 1 Distribution of topographic altitude of southern China. Note that the black box roughly represents the location of the YunnanGuizhou Plateau, and the west and east black asterisks represent the location of Kunming (the provincial capital of Yunnan) and Guiyang (the provincial capital of Guizhou), respectively

plateau, a quasi-stationary front is thus formed on the slope roughly between the two provinces. As one of the key weather systems in southwestern China during the winter half year, YGQSF is characterized by a sharp contrast of the weather conditions on its two sides, with severe cold, cloudy weather and freezing disasters in Guizhou but mild sunny weather in Yunnan (Deng et al. 2012; Du et al. 2015; Tao et al. 2018; Yang et al. 2011; Zhao et al. 2008; Zhou et al. 2011).

Previous case studies identified the synoptic structure of YGQSF and found some common features existing among individual cases. YGQSF is roughly a north-south-orientated front located between Yunnan and Guizhou, with a vertical height below $700 \mathrm{hPa}$ (Du et al. 2007a; Duan et al. 2002; Egger \& Tao 1992). Properties of the air masses on both sides of the front are in huge difference, with warm and dry conditions in the west but cold and wet conditions in the east (Du et al. 2007a; Duan et al. 2002). In addition, a clockwise secondary zonal circulation exists in the east of YGQSF (Duan et al. 2002; Li 1999; Lu et al. 2019; Xiao et al. 2019). However, the structure of YGQSF also exhibits some differences from event to event. In some cases, a thermal inversion layer appears in the east of YGQSF (Deng et al. 2015; Du et al. 2014, 2010; Du \& Lan 2010; Li et al. 2009; Qian \& Fu 2010; Yang et al. 2009), while in other cases it is absent (Du \& Lan 2010; Duan et al. 2002). This demonstrates that the characteristics of YGQSF derived from synoptic events depend on the selection of those events. In order to comprehensively capture the general characteristics of YGQSF, it is necessary to conduct the investigation from a climate perspective.
A few previous studies revealed the occurrence frequency of YGQSF by simply counting the number of YGQSF events. For example, Du et al. (2007b) indicated that the YGQSF activity features a seasonal variation with a high occurrence frequency from December to May and a low frequency from June to November. Zhang et al. (2016) pointed out that the number of YGQSF events exhibits a decreasing trend from 1970 to 2009. It is worth noting that the YGQSF events defined in previous studies are identified empirically, which would induce subjective uncertainties in quantifying YGQSF. Meanwhile, the statistical methods used in previous studies are only for the occurrence frequency of YGQSF events but not for the frontal intensity, which would limit the comprehensive understanding of YGQSF and its variations.

Therefore, it is necessary to propose a more objective method to identify and quantify YGQSF. During the past decades, how to objectively identify fronts on the isobaric surface was widely discussed (Hewson 1998; Hope et al. 2014; Kašpar 2003a, b; McCann and Whistler 2001; Renard and Clarke 1965). Based on the thermodynamic method proposed by Hewson (1998), Zhao et al. (2019) recognized three YGQSF events occurring at $850 \mathrm{hPa}$ in early 2008 , although it is difficult to recognize a low-level front over the complex terrain (Jenkner et al. 2010). However, this singleisobaric-surface-based method is not applicable anymore when YGQSF moves westward to higher land. The detection methods relying on the isobaric surface are not suitable for YGQSF due to the huge topographic change in Yunnan-Guizhou Plateau. Considering the unique topography, Duan et al. (2017) provided a method especially for identifying YGQSF, but the criteria used in this method are still overly dependent on the subjective experience from weather analysis. How to objectively identify and quantify YGQSF is still an open question.

This study intends to present a comprehensive investigation on the structure, variation, and impact of YGQSF from a climate perspective. Specifically, this study defines three indexes to quantitatively characterize YGQSF based on both topographic features of Yunnan-Guizhou Plateau and objective criteria. With these quantified indexes, the climatological structure, the subseasonal variability as well as the climatic impact of YGQSF are examined with longterm high-resolution atmospheric reanalysis data and observations from high-density stations.

The rest of the paper is structured as follows. Section 2 describes the dataset used. Section 3 defines three indexes to quantify the intensity, frequency, and location of YGQSF, respectively. In Sect. 4, the climatological characteristics of wintertime YGQSF are revealed. The atmospheric anomalies associated with the subseasonal variation of the YGQSF intensity are presented in Sect. 5. The final section is devoted to summary and discussion. 


\section{Datasets used}

The National Center for Environmental Prediction (NCEP) Climate Forecast System Reanalysis (CFSR) dataset with a horizontal resolution of $0.5^{\circ} \times 0.5^{\circ}$ for the period of 1981-2016 is used to analyze the structure and variation of YGQSF and associated atmospheric circulation. Daily atmospheric variables taken from the reanalysis include air temperature, wind velocity, and specific humidity at 27 standard pressure levels from 1000 to $100 \mathrm{hPa}$, and air potential temperature and wind velocity at the level of sigma 0.995 . In addition, the daily cloud cover fraction and specific cloud liquid water content at 27 standard pressure levels from 1000 to $100 \mathrm{hPa}$, obtained from ERA-Interim reanalysis with the horizontal resolution of $0.5^{\circ} \times 0.5^{\circ}$ for 1981-2016 of European Centre for Medium-Range Weather Forecasts, are used to analyze the cloud distribution related to YGQSF. Overlapping variables (i.e., air temperature, wind velocity, and specific humidity at 27 standard pressure levels from 1000 to $100 \mathrm{hPa}$ ) in both the CFSR and ERA-Interim reanalyses depict consistent results, and only the results for these variables with the CFSR reanalysis are shown in this paper.

The dataset of records at more than 2000 stations in China including daily maximum air temperature, daily sunshine duration, and daily precipitation for 1981-2016, taken from the National Meteorological Information Center of the China Meteorological Administration, is used to analyze the climatic impact of YGQSF. According to the precipitation from this dataset, a new variable, the rainfall frequency, is defined to describe the continuously rainy weather. A day with precipitation of more than $0.1 \mathrm{~mm}$ is defined as a rainy day (Wang et al. 2017), and a 7-day window mean of the number of rainy days is defined as the rainfall frequency.

In this study, the wintertime refers to January-March (JFM), since YGQSF is the strongest and the most frequently occurring during this period. To extract subseasonal variabilities, removals of firstly the climatological annual cycle and then the yearly JFM mean (i.e., interannual signals) are applied to all the data to get daily anomalies.

\section{Indexes quantifying YGQSF}

Considering the large terrain height difference between the eastern and western parts of Yunnan-Guizhou Plateau, it is appropriate to delineate YGQSF with air potential temperature and its gradient at terrain-following levels, which can avoid the effect of vertical temperature lapse rate induced by the terrain (Duan et al. 2017, 2018b). In this study, the horizontal air potential temperature gradient at the level of sigma 0.995 is calculated in terms of $\left|\nabla_{h} \theta\right|=\sqrt{\left(\frac{\partial \theta}{\partial x}\right)^{2}+\left(\frac{\partial \theta}{\partial y}\right)^{2}}$ to quantify the front.

Figure 2 shows the spatial distributions of climatological air potential temperature and its horizontal gradient at the level of sigma 0.995 over the Yunnan-Guizhou Plateau (labeled by the black box in Fig. 1) in January, April, July, and October, respectively. Dense contours of air potential temperature and its large gradients mainly exist meridionally between $103^{\circ} \mathrm{E}$ and $106^{\circ} \mathrm{E}$ in the whole year, with the maximum gradient in January and the minimum gradient in July. The air potential temperature in the west
Fig. 2 Horizontal distributions of climatological air potential temperature (contour, units: $\mathrm{K})$ and its horizontal gradient (shaded, units: $10^{-2} \mathrm{~K} \mathrm{~km}^{-1}$ ) at the level of sigma 0.995 over the Yunnan-Guizhou Plateau in a January, b April, c July, and d October, respectively, for 1981-2016. The red and blue boxes represent the western $\left(23.5^{\circ} \mathrm{N}-27^{\circ} \mathrm{N}\right.$, $\left.99^{\circ} \mathrm{E}-104.5^{\circ} \mathrm{E}\right)$ and eastern $\left(23.5^{\circ} \mathrm{N}-27^{\circ} \mathrm{N}\right.$, $\left.104.5^{\circ} \mathrm{E}-110^{\circ} \mathrm{E}\right)$ parts of the Yunnan-Guizhou Plateau, respectively; and the green box represents the frontal zone of YGQSF $\left(23.5^{\circ} \mathrm{N}-27^{\circ} \mathrm{N}\right.$, $\left.103^{\circ} \mathrm{E}-106^{\circ} \mathrm{E}\right)$. The left (right) black asterisk represents Kunming (Guiyang), as in Fig. 1

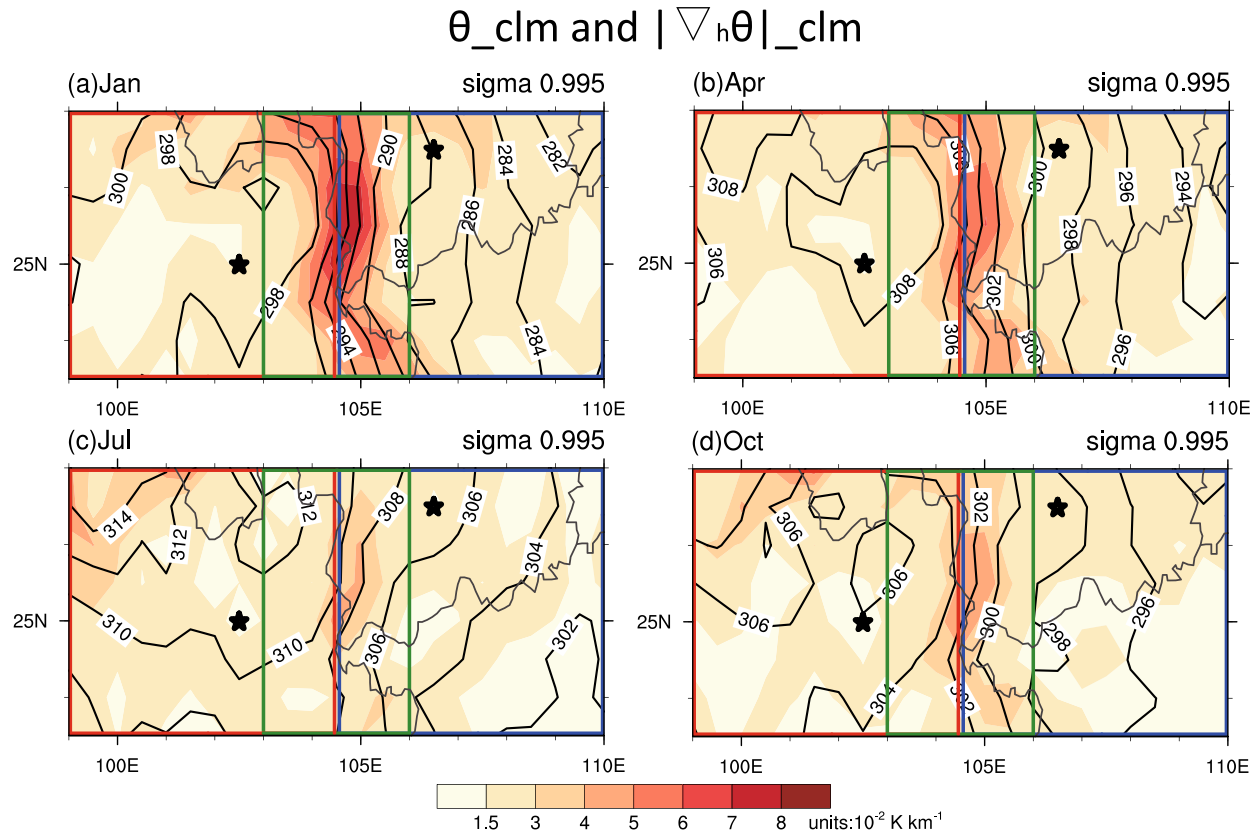


is higher than that in the east. This result provides clear evidence that YGQSF is a climatological front north-south oriented between Yunnan and Guizhou and is the most significant in winter. Thus, YGQSF can be climatologically recognized as the large horizontal air potential temperature gradients at the level of sigma 0.995 in the region of $23.5^{\circ} \mathrm{N}-27^{\circ} \mathrm{N}$, and $103^{\circ} \mathrm{E}-106^{\circ} \mathrm{E}$, labeled by the green box in Fig. 2. Given those facts, three daily indexes are objectively defined in this study to quantify the intensity, frequency, and location of YGQSF, respectively, in terms of the air potential temperature gradients at the level of sigma 0.995 .

An index quantifying the YGQSF intensity is defined as the regionally-averaged horizontal air potential temperature gradients that are greater than a threshold value within the frontal zone (the green box in Fig. 2). Considering the climatological distribution of the gradients in different seasons (Fig. 2), the threshold value is set to be $1.5 \mathrm{~K} / 100 \mathrm{~km}$. The concrete formula for calculating the daily intensity index of YGQSF, its, is written as:

$i t s_{i}=\frac{1}{N_{i}} \sum_{j=1}^{N_{i}}\left|\nabla_{h} \theta_{i j}\right|$

where $\left|\nabla_{h} \theta_{i j}\right|$ is the horizontal air potential temperature gradient at the level of sigma 0.995 with a criterion that the gradient must be larger than $1.5 \times 10^{-2} \mathrm{~K} \mathrm{~km}^{-1}$ at the $j$ th grid point within the frontal zone in the ith day, and $N_{i}$ is the number of the total grid point satisfying the criterion in the ith day. A large its means a strong YGQSF, and vice versa.

In order to measure the activity of YGQSF, an index quantifying the occurrence frequency of YGQSF is defined as the 7-day window mean of the number of days with the YGQSF intensity index (its) greater than $3 \mathrm{~K} / 100 \mathrm{~km}$ (the rounding of whole-year-mean climatological YGQSF intensity), which is written as:

$\mathrm{frq}_{i}=\frac{1}{7} \sum_{l=i-3}^{i+3} k_{l} ; \quad k_{l}=\begin{aligned} & 1 \text { its }_{l}>3 \\ & 0 \text { its }_{l} \leq 3\end{aligned}$,

where $k_{l}$ indicates if the $l$ th day is a strong-YGQSF day or not. If the its is greater than $3 \times 10^{-2} \mathrm{~K} \mathrm{~km}^{-1}$ in the lth day, then YGQSF is relatively strong and $k_{l}$ is et to be 1 , else $k_{l}$ equals 0 . Therefore, a large frq means that YGQSF occurs frequently and lasts long.

Here the location of YGQSF is focused on its longitude shift as YGQSF generally is a north-south-orientated front (Fig. 2). The longitude index is defined as a weightedaverage of the longitude with respect to the horizontal air potential temperature gradients at the level of sigma 0.995 greater than $1.5 \times 10^{-2} \mathrm{~K} \mathrm{~km}^{-1}$ within the frontal zone, which is written as:
$\operatorname{lon}_{i}=\frac{\sum_{j=1}^{N_{i}}\left|\nabla_{h} \theta_{i j}\right| \times L O N_{i j}}{\sum_{j=1}^{N_{i}}\left|\nabla_{h} \theta_{i j}\right|}$,

where $L O N_{i j}$ is the longitude of $j$ th grid point within the frontal zone with $\left|\nabla_{h} \theta_{i j}\right|$ greater than $1.5 \times 10^{-2} \mathrm{~K} \mathrm{~km}^{-1}$ in the ith day. The lon denotes the YGQSF location in longitude, and a large lon means that YGQSF has an eastward shift.

\section{Climatological characteristics of YGQSF}

In terms of the above defined three indexes, the climatological seasonal evolution of YGQSF can be analyzed in detail. Figure 3 shows the climatological annual cycles of the YGQSF indexes, as well as the regional-averaged air potential temperatures at the level of sigma 0.995 on the western and eastern sides of YGQSF, respectively. The intensity and frequency indexes of YGQSF are in phase with each other, with an increase from August to January and a decrease from February to July (Fig. 3a, b). Both of these two indexes peak at around January to March (JFM), indicating that YGQSF is the strongest, the most frequently occurring, and the longest-lasting during JFM, consistent with the result of counting the number of individual YGQSF events (Du et al. 2007b). During the increase (decrease) of YGQSF intensity and frequency from August to January (from February to July), the cooling (warming) on the eastern side (blue line in Fig. 3d) is more rapid than that on the western side (red line in Fig. 3d). These results demonstrate that it is the cold air in the east that plays the leading role in the seasonal evolution of YGQSF. As for the longitude location of YGQSF, it stays at around $104.6^{\circ} \mathrm{E}$ in the whole year, with a slight west-east shift within $0.5^{\circ}$ longitudes (Fig. $3 \mathrm{c}$ ). Although the zonal movements of YGQSF are found on a synoptic timescale (Zhang and Duan 2018), the quasi-stationary characteristic of the front found here is prominent in climatology.

During JFM when YGQSF is the strongest and the longest-lasting, the climate in the Yunnan-Guizhou region is significantly associated with the front. Figure 4 shows horizontal distributions of the climatological JFM daily maximum air temperature, sunshine duration, precipitation, and rainfall frequency according to the high-density station records in southern China. A striking feature is that the wintertime climates in Yunnan and Guizhou are dramatically different although their geographic locations are both at around $25^{\circ} \mathrm{N}$. Compared to warm and sunny Yunnan, Guizhou is much colder (Fig. 4a) and sunless (Fig. 4b), with more precipitation (Fig. 4c) and more frequent rain (Fig. 4d). In eastern China, the rainfall frequency is comparable to that in Guizhou (Fig. 4d), but the precipitation is much larger 
(a)YGQSF_its_clm

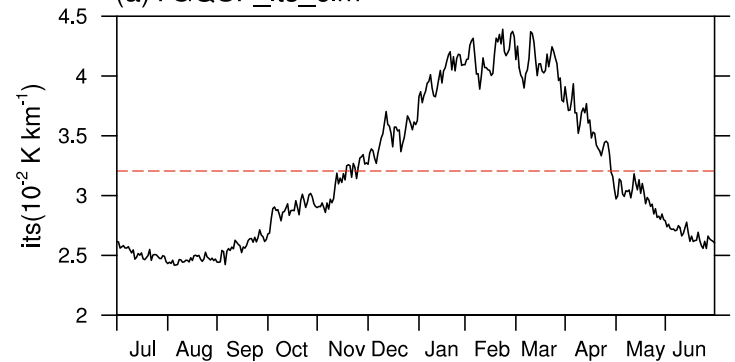

(c)YGQSF_lon_clm

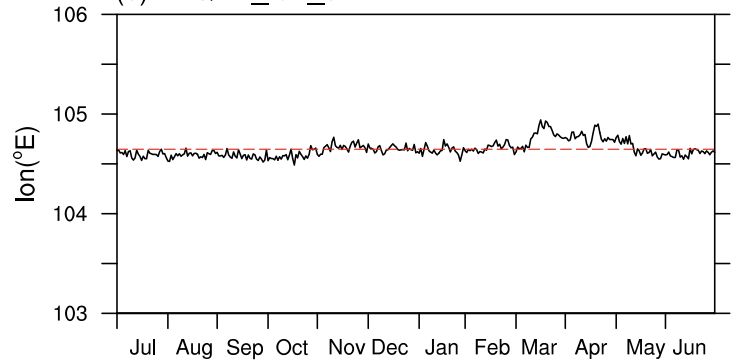

Fig. 3 Climatological seasonal evolutions of daily a YGQSF intensity index (units: $10^{-2} \mathrm{~K} \mathrm{~km}^{-1}$ ), b YGQSF frequency index (units: \%), c YGQSF location index (units: ${ }^{\circ} \mathrm{E}$ ), and $\mathbf{d}$ potential temperature at the level of sigma 0.995 averaged over the western part (red line, units:

\section{(b)YGQSF frq $\mathrm{clm}$}

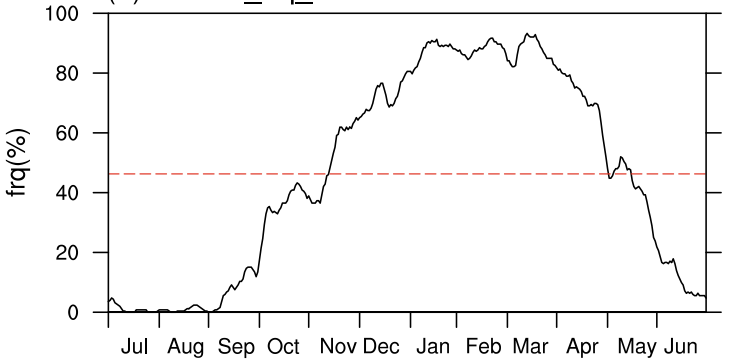

(d) $\theta$ Clm at sigma 0.995

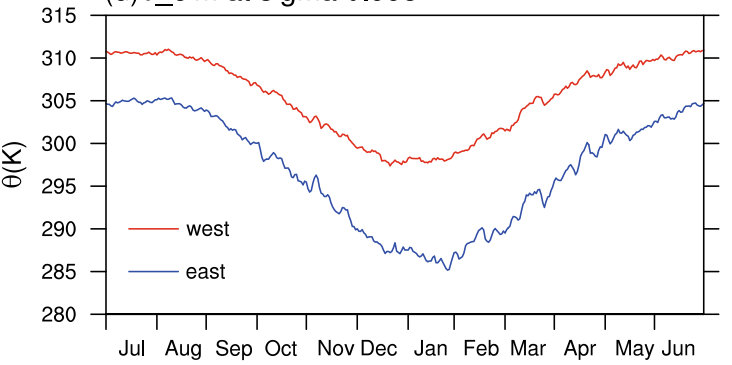

K) and eastern part (blue line, units: K) of the Yunnan-Guizhou Plateau, respectively, for 1981-2016. The red dash lines in (a), (b) and

(c) represent the climatological annual means

Fig. 4 Horizontal distributions of climatological a daily maximum air temperature (units:

$\left.{ }^{\circ} \mathrm{C}\right)$, b daily sunshine duration (units: $\mathrm{hr} \mathrm{day}^{-1}$ ), c daily precipitation (units: $\mathrm{mm} \mathrm{day}^{-1}$ ), and $\mathbf{d}$ rainfall frequency (units: \%) in southern China during JFM for 1981-2016, based on the station records
(a)max_temp_clm(JFM)

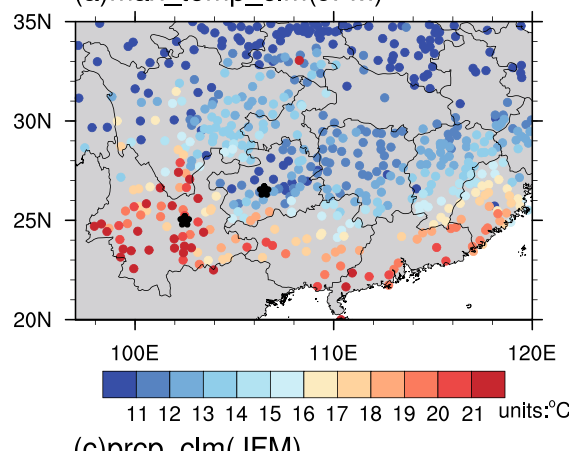
(c)prcp_clm(JFM)

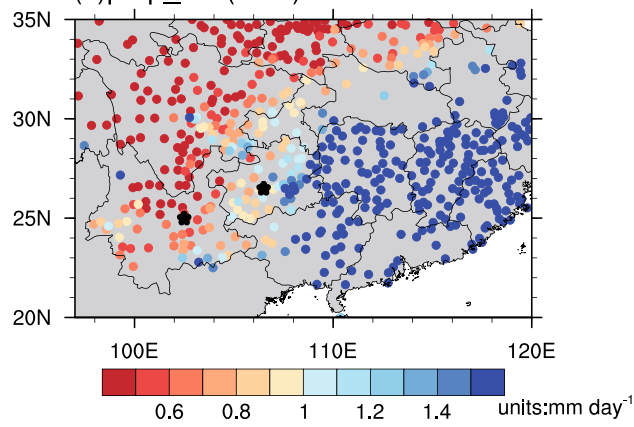

(b)ssd_clm(JFM)

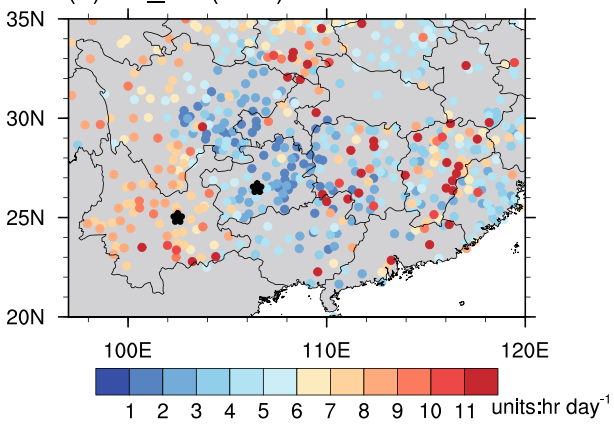

(d)rain_frq_clm(JFM)

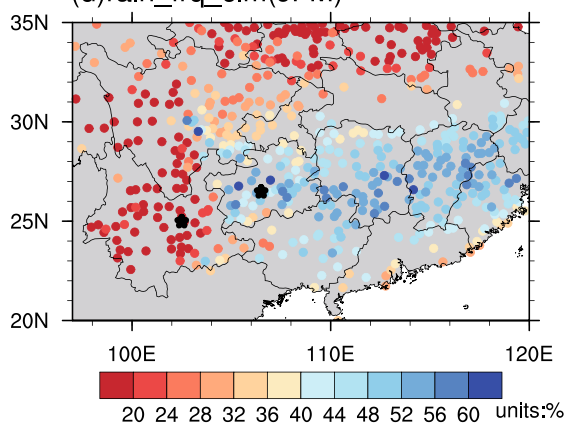

(Fig. 4c). This result is supported by $\mathrm{Li}$ and $\mathrm{Yu}$ (2014) which demonstrated that the precipitation over the Yunnan-Guizhou Plateau is more concentrated in weak events compared to that in southeastern China. The climate related to YGQSF is distinct from that in other regions, showing a sharp contrast between the two sides of YGQSF: Guizhou in the east is invariably cold, sunless, and rainy, while Yunnan in the west is always warm and sunny.

According to previous case analyses on synoptic timescale, the vertical structure of YGQSF plays an important 
Fig. 5 Longitude-altitude sections averaged between $23.5^{\circ} \mathrm{N}$ and $27^{\circ} \mathrm{N}$ of climatological a air potential temperature (black contour, units: $\mathrm{K}$ ) and its deviation from the zonal mean between $99^{\circ} \mathrm{E}$ and $110^{\circ} \mathrm{E}$ (shaded, units: $\mathrm{K}$ ), and horizontal air potential temperature gradient (green contour, units: $10^{-2} \mathrm{~K} \mathrm{~km}^{-1}$ ), b zonal and vertical wind vector (vector, units: $\mathrm{m} \mathrm{s}^{-1}$ ), c specific humidity (contour, units: $\mathrm{g} \mathrm{kg}^{-1}$ ) and its deviation from the zonal mean between $99^{\circ} \mathrm{E}$ and $110^{\circ} \mathrm{E}$ (shaded, units: $\mathrm{g} \mathrm{kg}^{-1}$ ), and $\mathbf{d}$ fraction of cloud cover (shaded, units:\%) and specific cloud liquid water content (contour, units: $10^{-2} \mathrm{~g} \mathrm{~kg}^{-1}$ ) over the Yunnan-Guizhou Plateau, during JFM for 1981-2016. The red line in $\mathbf{b}$ represents the zero line of climatological zonal wind velocity. The gray shadings represent the topography, and the western and eastern black asterisks represent the location of Kunming and Guiyang, respectively
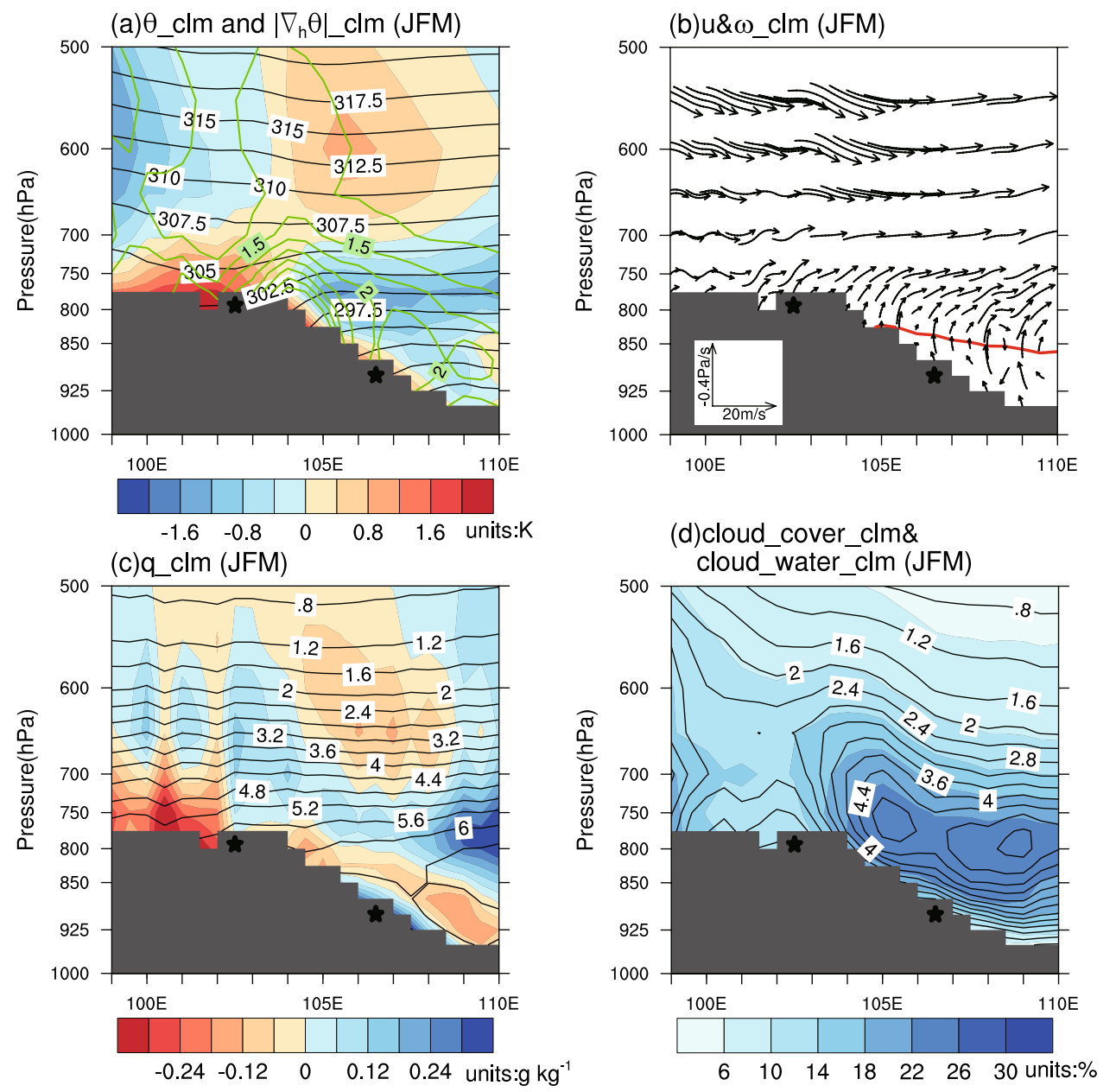

role in the extreme weather near the front (Du et al. 2014; Lu et al. 2019; Xiao et al. 2019; Yang et al. 2009). Similarly, the above climate impact of YGQSF during JFM is closely related to its climatological vertical structure. Figure 5 presents vertical distributions of the climatological JFM air potential temperature and its horizontal gradients, zonal and vertical wind, specific humidity, fraction of cloud cover, and cloud water content averaged between $23.5^{\circ} \mathrm{N}$ and $27^{\circ} \mathrm{N}$ over the Yunnan-Guizhou Plateau, respectively. As shown in Fig. 5a, the climatological air potential temperature shows a contrast of the warm west versus the cold east above the terrain and below $700 \mathrm{hPa}$, with the large gradients located between $104^{\circ} \mathrm{E}$ and $105^{\circ} \mathrm{E}$. This indicates that the climatological YGQSF is a shallow system below $700 \mathrm{hPa}$. The near-surface easterly wind below $850 \mathrm{hPa}$ in the eastern part of the plateau veers upward due to the obstruction of the western higher terrain. Beyond that, the frontal zone is nearly controlled by the westerly wind at the upper layer (Fig. 5b). Most of the moistures concentrate in the lower troposphere to the east of YGQSF. A contrast of the dry west versus the wet east at the same altitude is found above the terrain and below $700 \mathrm{hPa}$, with the strongest contrast at around $750 \mathrm{hPa}$ (Fig. 5c). Influenced by such a climatological configuration of ascending motion and abundant moisture in the east of YGQSF, the fraction of cloud cover and cloud liquid water content are also large there (Figs. 5d). It is such low-level clouds that cause the sunless and continuously rainy climate in Guizhou.

The structure of YGQSF is a local embodiment in this region of the large-scale atmospheric circulation. In previous studies focusing on synoptic timescale, the formation of YGQSF is found to be influenced by the terrain height difference between the eastern and western parts of the Yunnan-Guizhou Plateau (Duan et al. 2018a; Li et al. 2011; Sun \& Zhao 2010; Suo \& Ding 2016; Wang et al. 2009) and the large-scale atmospheric circulation including the midlatitude trough/ridge and blocking (Ding et al. 2008; Du et al. 2014; Suo et al. 2018; Zhang and Duan 2017), the Hadley and Ferrel Cells (Du et al. 2007a), the Southern Branch Trough and the Western Pacific Subtropical High (Sun and Zhao 2010; Zhang et al. 2016). To climatologically analyze the large-scale atmospheric circulation associated with the structure of YGQSF discussed above, Fig. 6 shows the climatological JFM air potential temperature and horizontal 
Fig. 6 Horizontal distributions of climatological air potential temperature (shaded, units: K) and horizontal wind vector (vector, units: $\mathrm{m} \mathrm{s}^{-1}$ ) at a the level of sigma 0.995 and b $750 \mathrm{hPa}$, as well as specific humidity flux (vector, units: $10^{2} \mathrm{~g} \mathrm{~kg}^{-1} \mathrm{~m} \mathrm{~s}^{-1}$ ) and its divergence (shaded, units: $10^{-5} \mathrm{~g} \mathrm{~kg}^{-1} \mathrm{~s}^{-1}$ ) at $\mathbf{c}$ $850 \mathrm{hPa}$ and $\mathbf{d} 750 \mathrm{hPa}$ over East Asia, during JFM for 1981-2016. The black boxes represent the location of the Yunnan-Guizhou Plateau
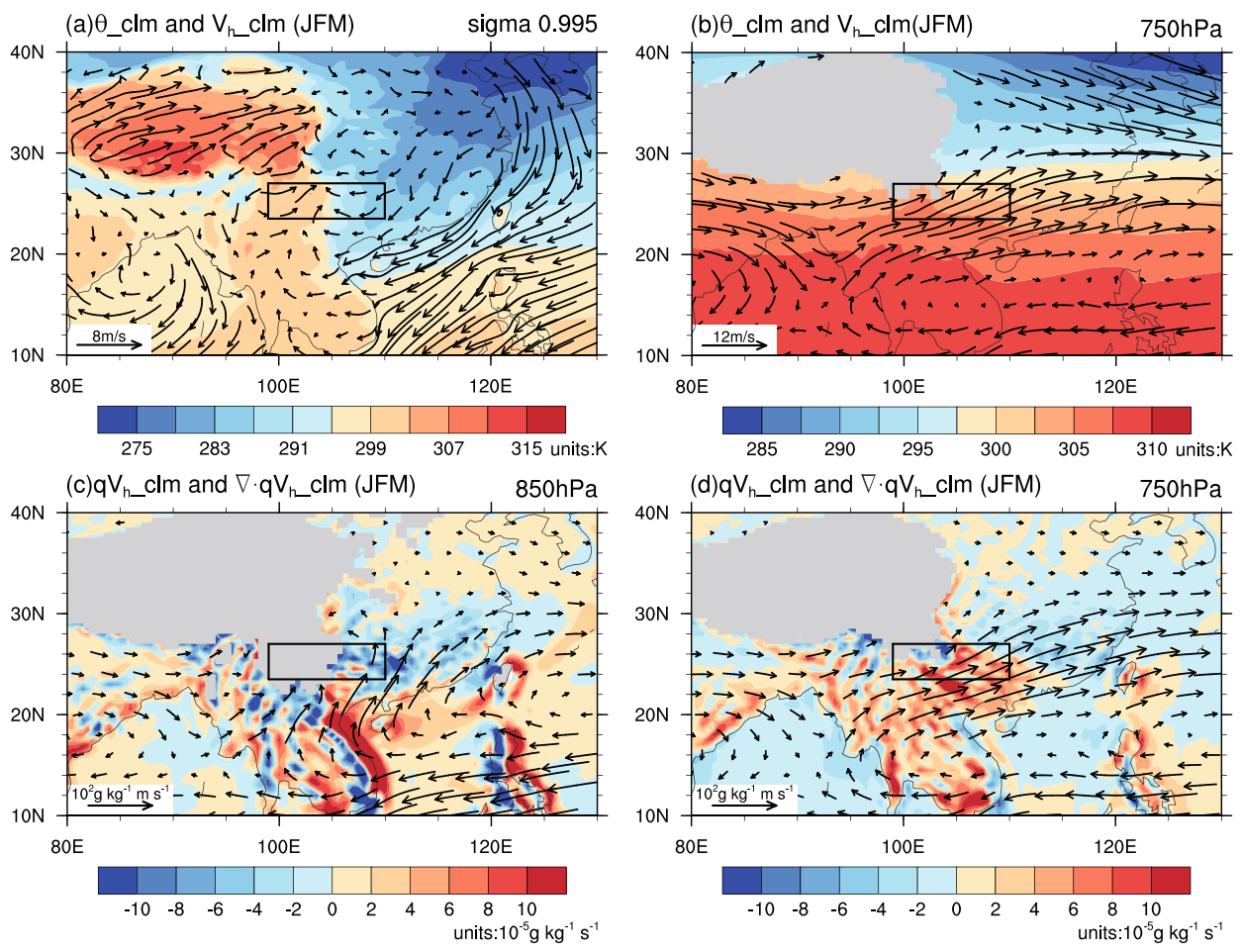

wind at sigma 0.995 and at $750 \mathrm{hPa}$, as well as the specific humidity flux and its divergence at $850 \mathrm{hPa}$ and $750 \mathrm{hPa}$ over East Asia. At sigma 0.995, the East Asian continent is mainly controlled by a surface cold high, accompanied by the southward intrusion of cold air from the midlatitudes into southern China. Located at the southwestern end of the surface cold high, the eastern part of Yunnan-Guizhou Plateau is influenced by the cold northeasterly wind. Besides, the southwesterly wind in the east of the Southern Branch Trough advects the warm air from the low-latitudes to the western part of the plateau (Fig. 6a). Due to the obstruction of the terrain, the cold northeasterly wind accumulates and veers upward in the eastern part of Yunnan-Guizhou Plateau and confronts the warm southwesterly wind in the western part, forming the climatological YGQSF. It is worth noting that the southwesterly warm wind at $750 \mathrm{hPa}$ originating from the Southern Branch Trough and the Western Pacific Subtropical High dominantly prevails over the Yunnan-Guizhou Plateau (Fig. 6b), without any horizontal advection of cold air. This demonstrates that the climatological YGQSF is a shallow system generated by the large-scale circulation near the surface. As for the moisture transport, at $750 \mathrm{hPa}$, where the specific humidity contrast between the west and east sides of YGQSF is the strongest (Fig. 5c), a divergence of specific humidity flux exists in the eastern part of the Yunnan-Guizhou Plateau (Fig. 6d), although the southwesterly winds in the east of the South Branch Trough and on the northwestern side of the Western Pacific Subtropical High transport moisture northeastward. However, at the lower altitude of $850 \mathrm{hPa}$, the moisture is transported northwestward and converges in the eastern part of the Yunnan-Guizhou Plateau (Fig. 6c). This implies that the strongest contrast of the dry west versus the wet east at $750 \mathrm{hPa}$ is not contributed by the horizontal transportation of moisture, but due to its upward transportation from the lower altitude.

\section{Subseasonal variation of YGQSF and associated atmospheric anomalies}

With the YGQSF indexes defined in Sect. 3, wavelet analysis is performed to investigate the characteristics of the YGQSF variation. The climatological time-frequency distributions of the YGQSF intensity, frequency, and location are shown in Fig. 7, in which the climatological wavelet power spectrum is shaded and the occurrence ratio of the wavelet power exceeding $90 \%$ confidence level in all analyzed years is contoured. The YGQSF intensity is characterized by two separate wavelet power centers in JFM, corresponding to two principal periods of around 30-day and 60-day, respectively, with significant occurrence ratios both more than $20 \%$. This indicates that the YGQSF intensity indeed exhibits significant subseasonal variation. As for the YGQSF frequency, large and significant subseasonal variation with the typical period of 30-60-day appears in November-December and April-May. However, its wavelet power is weak and insignificant during JFM when YGQSF exists almost steadily (Fig. 7b). The Longitude-location of YGQSF shows weak 
(a)wavelet power of YGQSF its

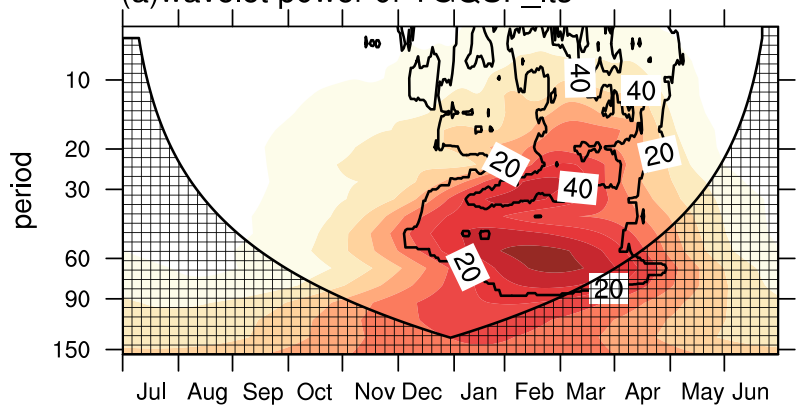

(b)wavelet power of YGQSF_fra

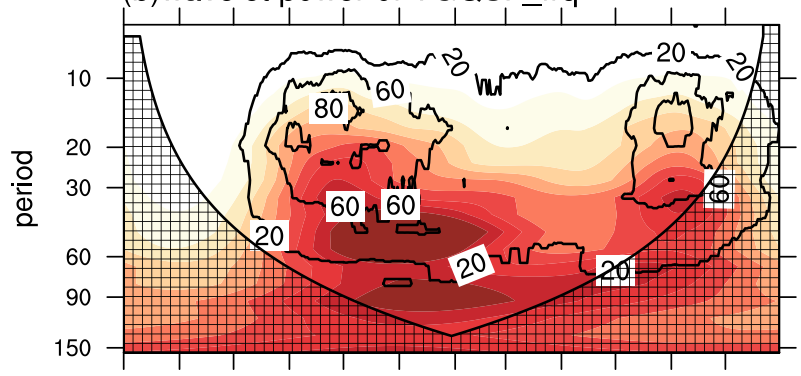

Jul Aug Sep Oct Nov Dec Jan Feb Mar Apr May Jun (c)wavelet power of YGQSF_lon

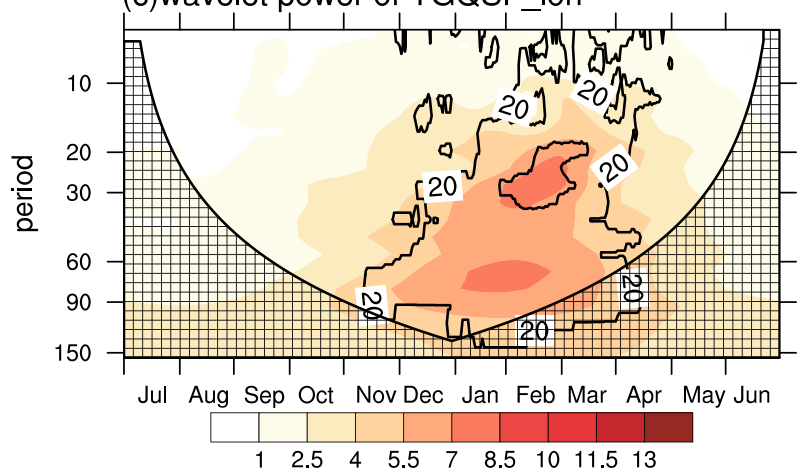

Fig. 7 Wavelet power spectrum (shaded) averaged from 1981 to 2016 and occurrence ratios (contours, units: \%) of the wavelet power exceeding 90\% confidence level (regular chi-square test) in 19812016 for standardized a intensity index, b frequency index, and c location index of YGQSF. The square-filled shadings are the cones of influence

subseasonal variation in JFM with two typical periods the same as those of the intensity (Fig. 7c), indicating that the east-west shift of YGQSF is quite weak on the subseasonal time scale.

Considering the strong and significant subseasonal variation of the YGQSF intensity in JFM, the structure and climate impact of an anomalously strengthened YGQSF on the subseasonal time scale are analyzed below through composite analysis. A strong YGQSF (Str_YGQSF) event is defined if the subseasonal anomaly of the daily YGQSF intensity that is obtained by removing the climatological annual cycle and the yearly JFM mean exceeds +1.5 standard deviation, and then 234 Str_YGQSF events are composited $\theta$ _ano and $\left|\nabla_{\mathrm{h} \theta} \theta\right|$ ano

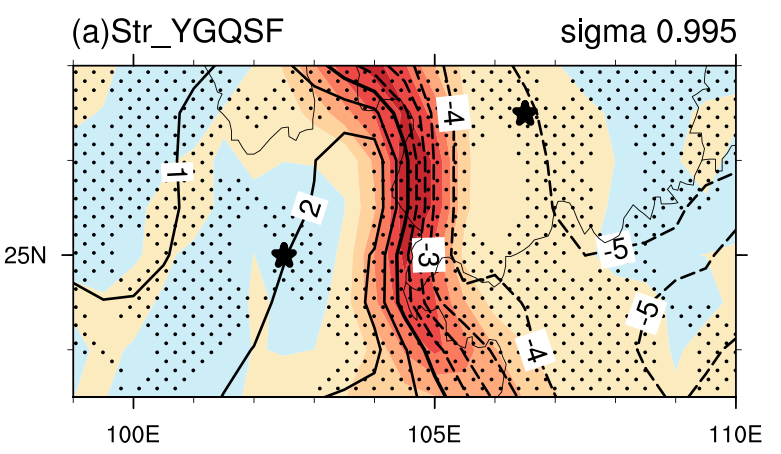

(b)CE_YGQSF sigma 0.995

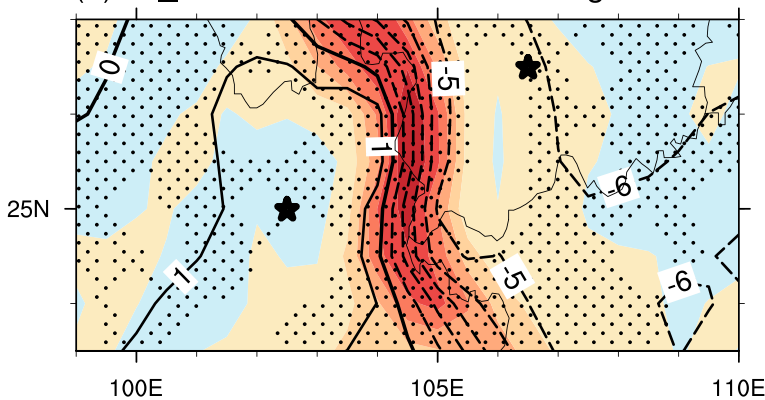

(c)WW YGQSF

sigma 0.995

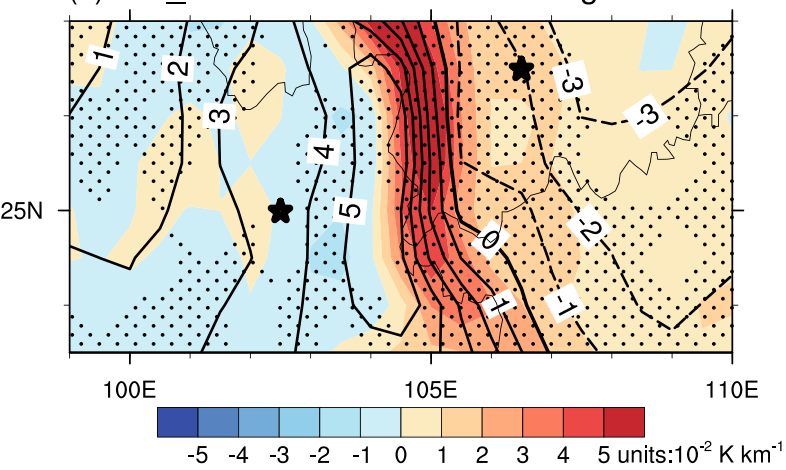

Fig. 8 Horizontal distributions of composite anomalies of air potential temperature (contour, units: $\mathrm{K}$ ) and its horizontal gradient (shaded, units: $10^{-2} \mathrm{~K} \mathrm{~km}^{-1}$ ) for a Str_YGQSF, b CE_YGQSF, and c WW_YGQSF at the level of sigma 0.995 over the Yunnan-Guizhou Plateau. The dots indicate the regions exceeding 95\% confidence level with the Student's $t$ test. The left (right) black asterisk represents Kunming (Guiyang), as in Fig. 1

identified in JFM for 1981-2016. To depict the anomalous horizontal thermal structure of the intensified YGQSF, Fig. 8a demonstrates composite air potential temperature anomalies and their horizontal gradients at the level of sigma 0.995 over the Yunnan-Guizhou Plateau for those Str_YGQSF events. The intensified YGQSF can be identified by the positive horizontal air potential temperature gradient anomalies. The distribution of the air potential temperature exhibits an anomalous cold-east and warmwest structure, with the cold anomaly in the east larger than the warm anomaly in the west, implying the leading 
role of the eastern cold anomaly in the enhancement of YGQSF on the subseasonal timescale.

It is recognized in Sect. 4 that the cold air and warm air respectively in the eastern and western parts of the Yunnan-Guizhou Plateau are induced by different large-scale circulation systems. Therefore, it is necessary to classify the Str_YGQSF events into the eastern cold anomalyinduced strong YGQSF cases (CE_YGQSF) and the western warm anomaly-induced strong YGQSF cases (WW YGQSF). A CE_YGQSF event is defined if a Str_YGQSF event with $\left.\mid \theta_{\text {west }}^{\prime}\right] /\left|\theta_{\text {east }}^{\prime}\right|<2 / 3$, where $\theta_{\text {west }}^{\prime}$ and $\theta_{\text {east }}^{\prime}$ represent the regional mean of air potential temperature anomaly at the level of sigma 0.995 within a western region $\left(23.5^{\circ} \mathrm{N}-27^{\circ} \mathrm{N}, 99^{\circ} \mathrm{E}-104.5^{\circ} \mathrm{E}\right)$ and an eastern region $\left(23.5^{\circ} \mathrm{N}-27^{\circ} \mathrm{N}, 104.5^{\circ} \mathrm{E}-110^{\circ} \mathrm{E}\right)$, respectively. A WW YGQSF event is defined if a Str_YGQSF event with $\left|\theta_{\text {west }}^{\prime}\right| /\left|\theta_{\text {east }}^{\prime}\right|>3 / 2$. In terms of these definitions, 169 CE_YGQSF events (around 75\% of Str_YGQSF) and 34 WW_YGQSF events (no more than $17 \%$ of Str_YGQSF) are distinguished. The huge difference between the numbers of these two kinds of Str_YGQSF events implies that the subseasonal enhancement of YGQSF is largely determined by the cold anomaly in the east. Anomalous horizontal thermal structures for CE_YGQSF and WW YGQSF are shown in Fig. 8b, c, respectively. It is obvious that the location of the positive horizontal air potential temperature gradient anomaly is slightly shifted westward in CE_YGQSF relative to that in WW_YGQSF, indicating that the strong eastern cold anomaly tends to induce the westward shift of anomalously enhanced YGQSF.

In order to clarify anomalous vertical structure of subseasonally intensified YGQSF, Fig. 9 gives longitude-altitude sections of composite anomalies of air potential temperature, zonal and vertical wind, specific humidity, cloud cover fraction, and cloud liquid water content averaged between $23.5^{\circ} \mathrm{N}$ and $27^{\circ} \mathrm{N}$ over the Yunnan-Guizhou Plateau for three kinds of categorized strong YGQSF events. For the Str_YGQSF events, i.e., the total strong YGQSF events (left panels of Fig. 9), a considerable cold anomaly exists below $800 \mathrm{hPa}$ in the eastern low-terrain region (east of $104.5^{\circ} \mathrm{E}$ ), compared to a relatively weak warm anomaly in the western high-terrain region (Fig. 9a). Above $800 \mathrm{hPa}$ the whole plateau is controlled by the anomalous westerly wind, while below $800 \mathrm{hPa}$ the anomalous easterly wind occurs in the eastern region and veers upward to around $700 \mathrm{hPa}$ (Fig. 9d), strengthening the climatological circulation. Such an anomalous ascending motion enhances the upward moisture transportation, leading to an anomalous structure in moisture with the upper-level wet anomaly centered at $750 \mathrm{hPa}$ and the lower-level dry anomaly below $800 \mathrm{hPa}$ (Fig. 9g). The eastern anomalous ascending motion also contributes to a positive cloud cover anomaly as well as a positive cloud water content anomaly below $600 \mathrm{hPa}$ (Figs. 9j).

As two subsets of Str_YGQSF, anomalous vertical structures for CE_YGQSF and WW_YGQSF are basically similar to that of Str_YGQSF, but differences are also found, as shown in central and right panels of Fig. 9, respectively. Firstly, a stronger cold anomaly expands more westward to $104^{\circ} \mathrm{E}$ and more upward to $750 \mathrm{hPa}$ for CE_YGQSF (Fig. 9b), while a stronger warm anomaly expands more eastward and the cold anomaly is restricted to the east of $106^{\circ} \mathrm{E}$ and below $850 \mathrm{hPa}$ for WW_YGQSF (Fig. 9c). Secondly, the anomalous easterly wind and ascending motion in the east are stronger and extend higher for CE_YGQSF (Fig. 9e) than for WW_YGQSF (Fig. 9f), transporting more moisture upward. Consequently, the eastern dry anomaly is stronger and extends more upward to $800 \mathrm{hPa}$ for CE_YGQSF (Fig. 9h), compared with the weaker one below $900 \mathrm{hPa}$ in WW_YGQSF (Fig. 9i). Meanwhile, positive cloud cover and cloud water content anomalies in the east expand upward to $600 \mathrm{hPa}$ for CE_YGQSF (Fig. 9k), which is significantly higher than those to $700 \mathrm{hPa}$ for WW_YGQSF (Fig. 91). Besides, the anomalous westerly wind over the plateau above the near-surface is stronger for WW_YGQSF (Fig. 9f) than for CE_YGQSF (Fig. 9e), promoting more moisture supply for the eastern region by stronger anomalous horizontal moisture transportation. Therefore, the moistening and the increased cloud cover and cloud water content are more significant in the east for WW_YGQSF (Fig. 9i and l). In addition, an apparent anomalous descending motion in the west is found for WW_YGQSF (Fig. 9f), while it is invisible for CE_YGQSF (Fig. 9e), which leads to a stronger negative cloud cover and cloud water content anomaly in the west for WW_YGQSF (Fig. 91).

The above anomalous structure for a subseasonally enhanced YGQSF has climate impacts in this region. Figure 10 shows composite anomalies of daily maximum air temperature, sunshine duration, precipitation, and rainfall frequency over Yunnan and Guizhou for Str_YGQSF, CE_ YGQSF, and WW_YGQSF, respectively. When YGQSF is enhanced, as an impact of the anomalous warm-west and cold-east structure and the increased cloud cover in the east, Guizhou is anomalously cold (Fig. 10a), short of sunshine (Fig. 10d), and continuously rainy (Fig. 10g, j), while Yunnan is anomalously warm (Fig. 10a) and sunny (Fig. 10d, g, and $\mathrm{j}$ ), largely enhancing the climatological contrast between the two provinces. As for the different climate impacts of CE_YGQSF and WW_YGQSF, it can be seen that the stronger cold anomaly and the positive cloud cover anomaly in the east contribute to the much colder (Fig. 10b, c) and cloudier (Fig. 10e,f) Guizhou for CE_YGQSF; the stronger warm anomaly and the negative cloud cover anomaly in the west lead to the warmer (Fig. 10b, c) and sunnier (Fig. 10e, $\mathrm{f}, \mathrm{h}, \mathrm{i}, \mathrm{k}$ and l) Yunnan for WW_YGQSF. It is worth noting 
(a)Str_YGQSF
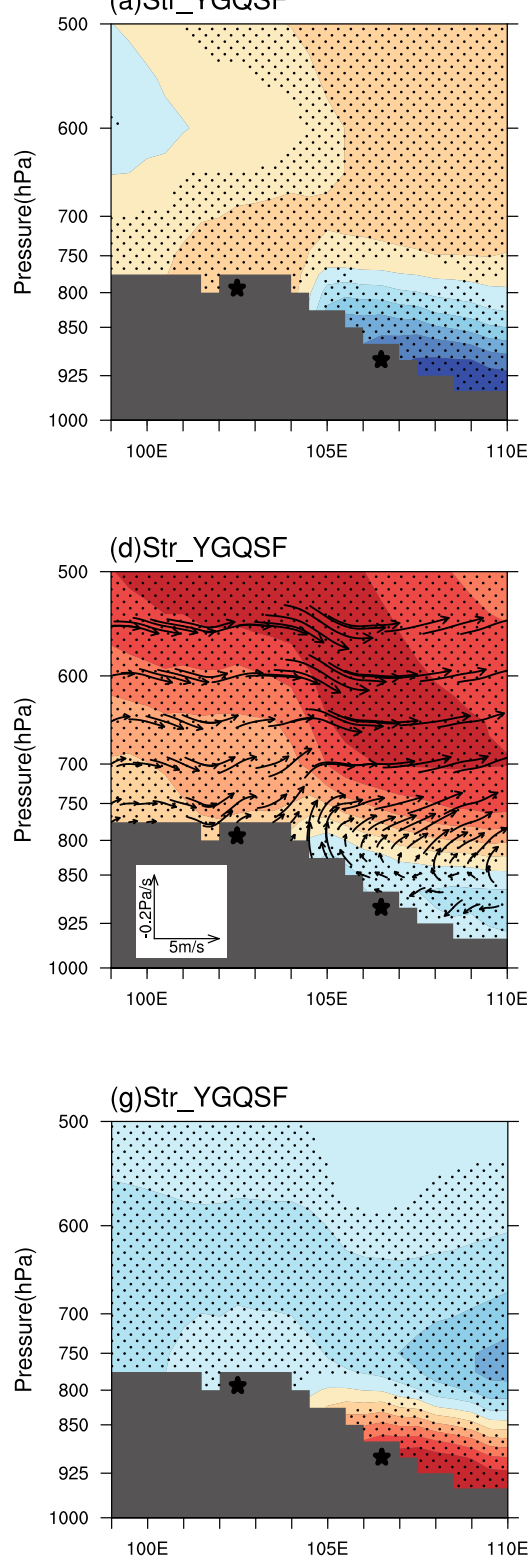

(d)Str_YGQSF

composited $\theta$ _ano

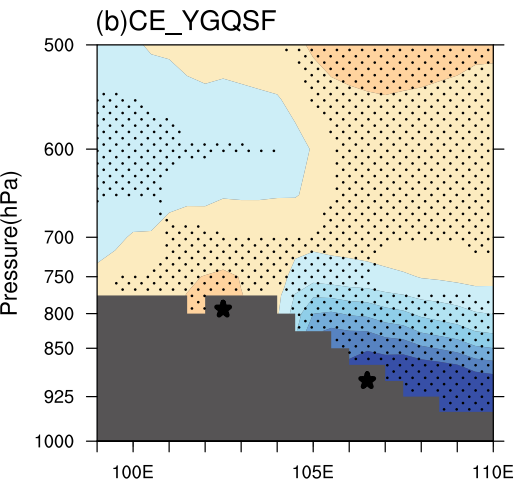

composited u_ano and u\&w_ano
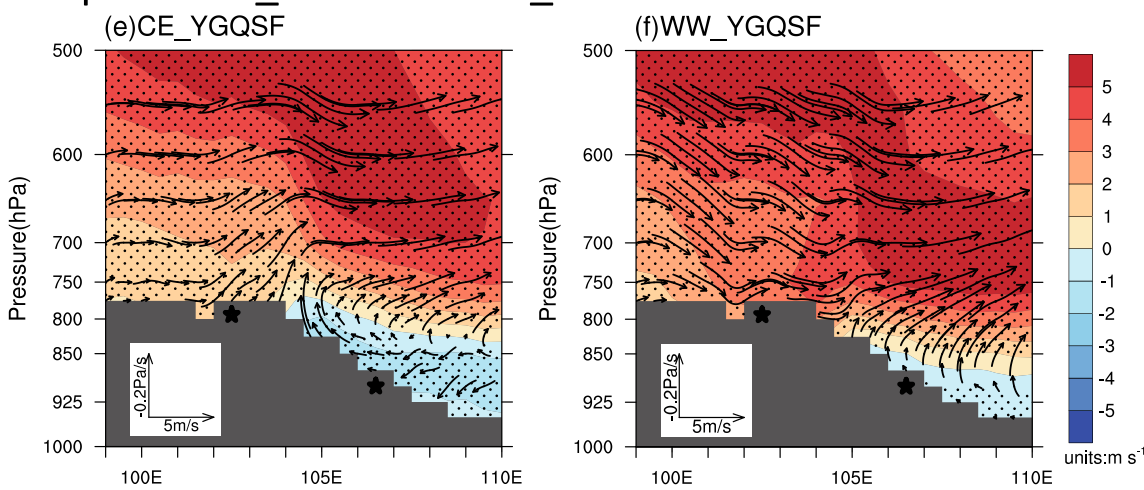

composited q_ano
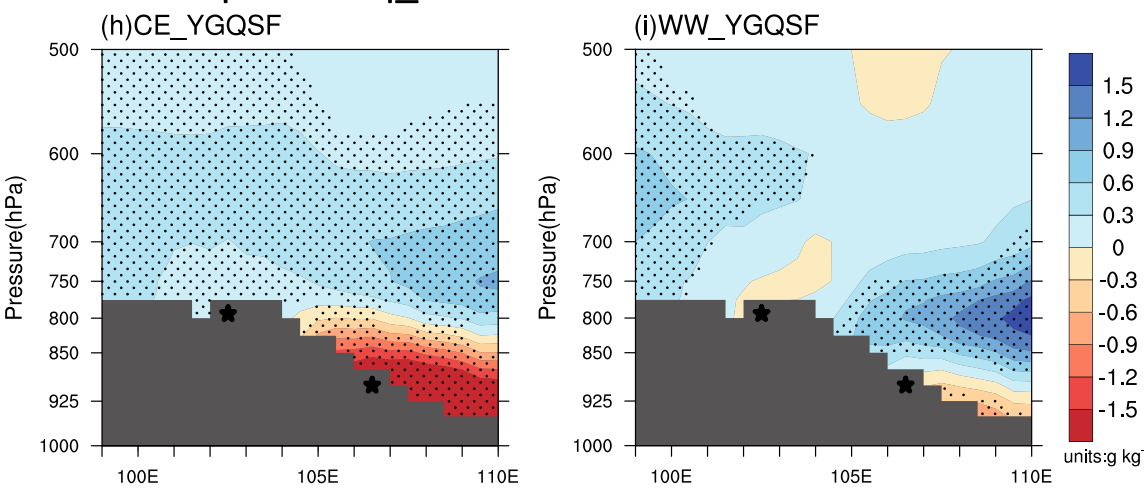

composited cloud_cover_ano and cloud_water_ano
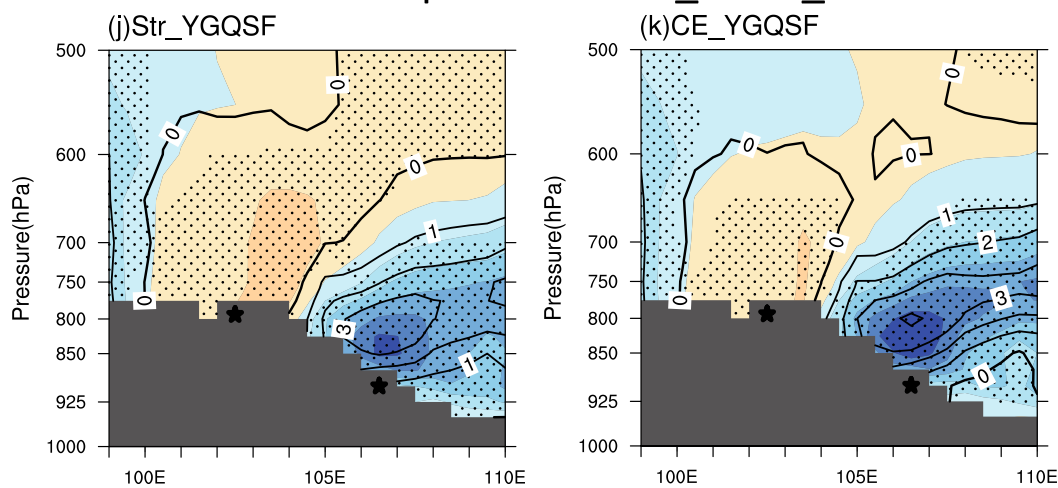
4Fig. 9 Longitude-altitude sections averaged between $23.5^{\circ} \mathrm{N}$ and $27^{\circ} \mathrm{N}$ of composite anomalies of a-c air potential temperature (shaded, units: K), d-f zonal wind velocity (shaded, units: $\mathrm{m} \mathrm{s}^{-1}$ ) and zonal and vertical wind vector (vector, units: $\mathrm{m} \mathrm{s}^{-1}$ ), $\mathbf{g}-\mathbf{i}$ specific humidity (shaded, units: $\mathrm{g} \mathrm{kg}^{-1}$ ), and $\mathbf{j}-\mathbf{l}$ fraction of cloud cover (shaded, units: \%) and specific cloud liquid water content (contour, units: $10^{-2} \mathrm{~g} \mathrm{~kg}^{-1}$ ) for Str_YGQSF (left panels), CE_YGSQF (central panels), and WW_YGQSF (right panels), respectively. The dots indicate the regions exceeding 95\% confidence level with the Student's $t$ test

that the positive rainfall frequency anomalies in Guizhou for CE_YGQSF and WW_YGQSF are basically in the same magnitude (Fig. 10k, 1). This is probably because the eastern cloud cover for CE_YGQSF is thicker but contains less moisture, while that for WW_YQSF is thinner but contains more moisture.

\section{Summary and discussion}

YGQSF is a unique synoptic phenomenon that frequently occurs during the winter half year over the Yunnan-Guizhou Plateau in southwestern China and considerably affects local weather and climate in this region. Most of the previous studies analyzed it only based on individual cases. This study extends the investigation to a climate perspective of the structure, variation, and impact of YGQSF, using longterm high-resolution atmospheric reanalysis data and observations of high-density stations for 1981-2016. Considering the terrain height difference between the western and eastern parts of the Yunnan-Guizhou Plateau, an objective method quantifying YGQSF is proposed and three indexes are defined to measure the intensity, frequency, and location of YGQSF, respectively, with the horizontal air potential temperature gradient at the level of sigma 0.995, a terrainfollowing level, avoiding the effect of vertical temperature lapse rate induced by the terrain. With these quantified indexes, the climatological structure, the subseasonal variability as well as the climatic impact of YGQSF are comprehensively examined.

In climatology, YGQSF is found to the most frequently occur and be the strongest during JFM, which is determined predominately by the coldness from the east of the front. It is a north-south-oriented front with an averaged location at around $104.6^{\circ} \mathrm{E}$ and a very slight zonal movement in the whole year.

Based on the results identified from this study, a summarized schematic diagram for the climatological structure of YGQSF during the winter half year is shown in Fig. 11a. The cold northeasterly winds from the surface cold high in East Asia are impeded by the high-terrain western part of the Yunnan-Guizhou Plateau, leading to an accumulation and an ascent of cold air coming from the low-terrain eastern part of the plateau. Thus, moistures are transported upward from the near-surface to $750 \mathrm{hPa}$ and low clouds are formed there. Meanwhile, the ascending cold air turns eastward at around $750 \mathrm{hPa}$, merging into the warm southwestern winds originating from the east of the South Branch Trough and inducing a downstream moistening. Therefore, although nearly located at the same latitude, Guizhou in the east of YGQSF is invariably cold, sunless, and rainy while Yunnan in the west is always warm and sunny, forming an intense climate contrast in the two sides of the front.

Wavelet analysis shows that the intensity of YGQSF is characterized by subseasonal variabilities with two significant principal periods at around 30-day and 60-day, respectively, during JFM. The subseasonal cold (warm) anomaly alone in the eastern (western) part of the Yunnan-Guizhou Plateau can enhance YGQSF, but the former accounts for nearly $75 \%$ of the strong YGQSF events while the latter no more than $17 \%$. As shown in Fig. $11 \mathrm{~b}$, c, for whether the eastern cold anomaly-induced strong YGQSF events (CE_YGQSF) or the western warm anomaly-induced strong YGQSF events (WW_YGQSF), anomalous near-surface easterly winds are obstructed by the western high terrain and veers upward in the eastern part. Thereby the upward moisture transportation is anomalously strengthened, leading to an anomalous upper-wet and lower-dry structure and an anomalous increase of clouds in the low-level atmosphere. Controlled by the anomalous cold air mass and increasing low-level clouds, Guizhou is anomalously cold, cloudy, and continuously rainy, while, affected by the anomalous warm air mass, Yunnan is anomalously warm and sunny, amplifying the climate contrast between two provinces.

Compared with WW_YGQSF, the anomalous easterly wind and the ascending motion of the eastern part are stronger and higher-reaching for CE_YGQSF, implying more upward moisture transportation. Thus the anomalous upper-wet and lower-dry structure and the anomalous increase of low-level clouds expand more westward and to higher troposphere in CE_YGQSF than in WW_YGQSF. Correspondingly, Guizhou is anomalously colder and cloudier. The anomalous westerly wind over the plateau above the near-surface is stronger in WW_YGQSF than in CE_YGQSF, promoting more moisture supply for the eastern part by stronger anomalous horizontal moisture transportation. Therefore, the anomalous increase of rainfall frequency of Guizhou in WW_YGQSF is comparable to that in CE_YGQSF. Besides, in WW_YGQSF there is an apparent anomalous descending motion in the western part that suppresses the cloud formation but is invisible in CE_YGQSF, inducing a much warmer and sunnier Yunnan directly in WW_YGQSF.

Climatologically, YGQSF is a local embodiment in this specific region of large-scale atmospheric circulation. Inferentially, the subseasonal variabilities of YGQSF are induced 
composited max_temp_ano

(a) Str YGQSF
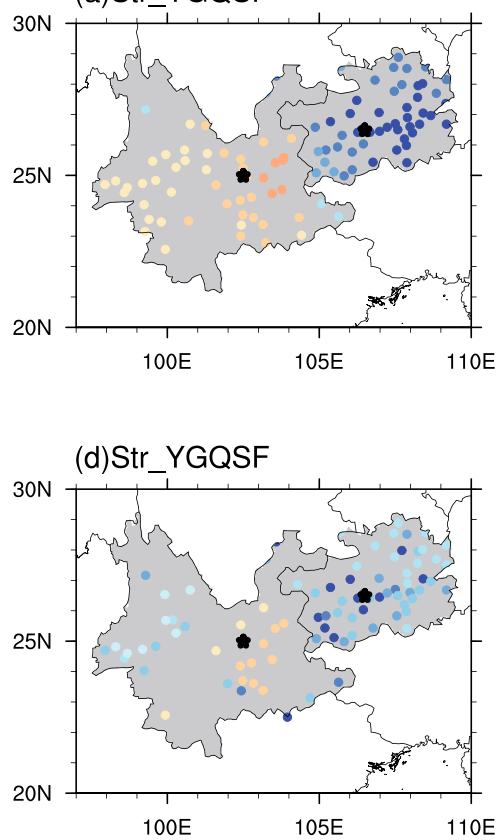

(d)Str_YGQSF
(b)CE_YGQSF

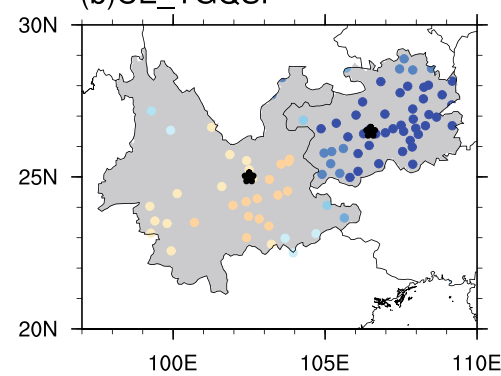
(e)CE_YGQSF

$110 \mathrm{E}$ composited ssd_ano

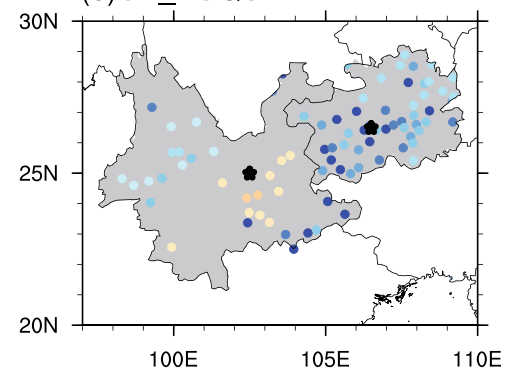

(c)WW YGQSF
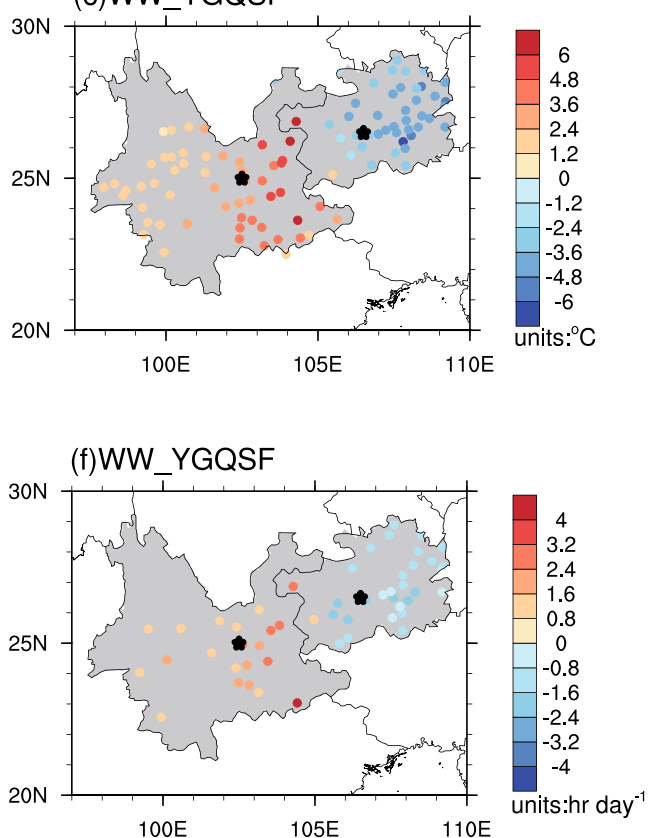

composited prcp_ano (h)CE_YGQSF

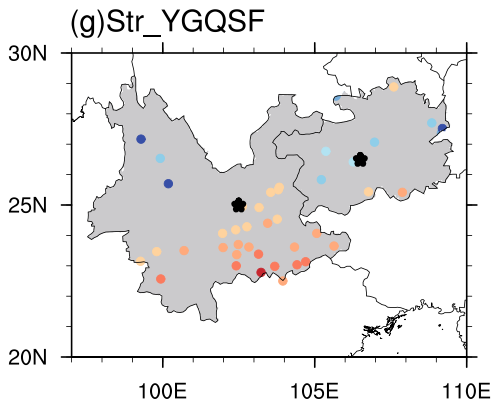

(i)WW_YGQSF

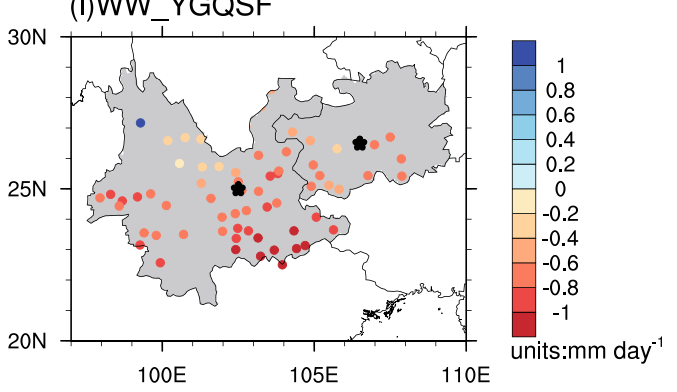

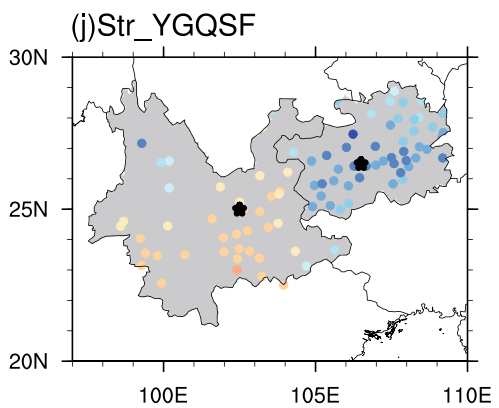

composited rain_frq_ano
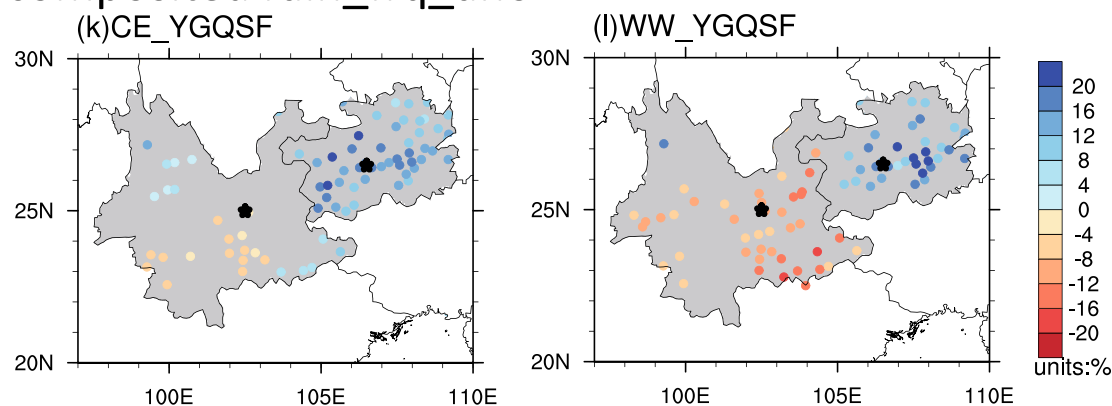

Fig. 10 Horizontal distributions of composite anomalies of $\mathbf{a}-\mathbf{c}$ daily maximum air temperature (units: ${ }^{\circ} \mathrm{C}$ ), $\mathbf{d}-\mathbf{f}$ daily sunshine duration (units: $\mathrm{hr} \mathrm{day}^{-1}$ ), $\mathbf{d}-\mathbf{i}$ daily precipitation (units: $\mathrm{mm} \mathrm{day}{ }^{-1}$ ), and $\mathbf{j}-\mathbf{l}$ rainfall frequency (units: \%) for Str_YGQSF (left panels), CE_

by the subseasonal variations of relevant large-scale atmospheric circulation. The YGQSF anomalies are majorly caused by the cold air activities which are more related to subseasonal variations of the mid- and high-latitude
YGQSF (central panels), and WW_YGQSF (right panels) in Yunnan and Guizhou Provinces, based on the station records. Note that only the values exceeding 95\% confidence level with the Student's $t$ test are plotted

atmospheric circulation. Moreover, the tropical atmosphere features significant intraseasonal oscillation, say, the Madden Julian Oscillation, during the winter half year, which may also affect the East Asian climate. Therefore, it is of 
Fig. 11 Schematic diagrams for the structures of a climatological YGQSF, b CE_YGQSF, and c WW_YGQSF (a) climatological YGQSF

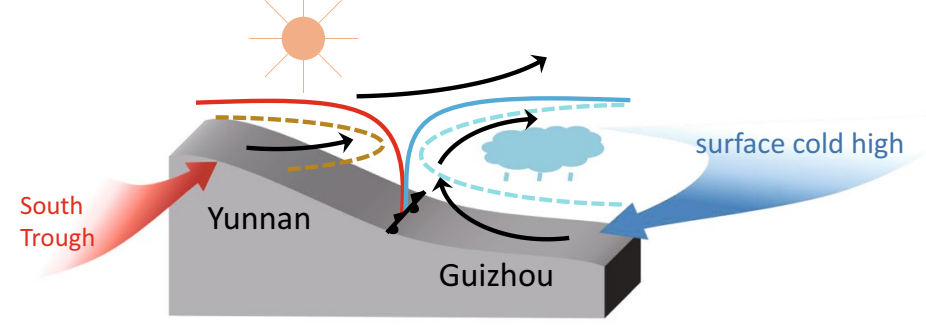

YGQSF

warm air

- cold air

- wet air
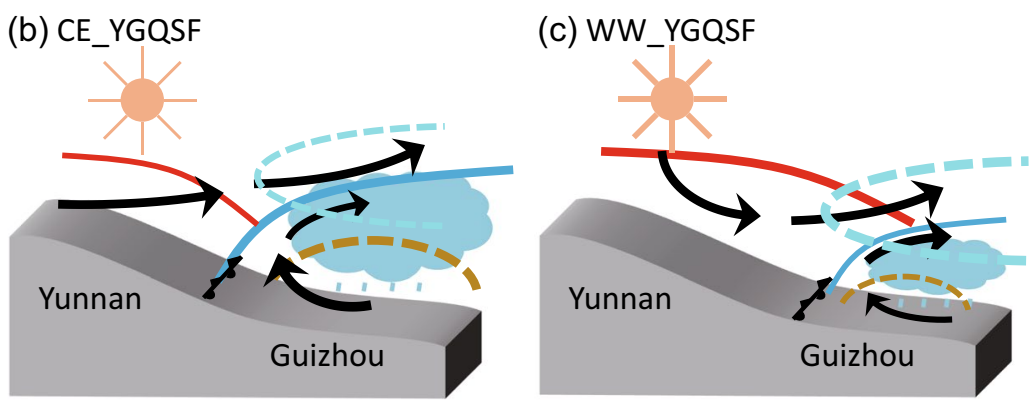

$=$ dry air

$\rightarrow$ wind

cloud cover

topography great importance to further investigate the impact of subseasonal signatures originating from the mid- and high-latitudes as well as from the tropics for understanding and predicting the YGQSF anomalies, although it is still a challenging issue to be solved.

Acknowledgements This work is jointly supported by the National Key R\&D Program of China (2018YFC1505902) and the National Natural Science Foundation of China $(41865007,42042013,41621005)$. We are also grateful for support from the Jiangsu Collaborative Innovation Center for Climate Change. The CFSR data was provided by Research Data Archive at the National Center for Atmospheric Research and is available at https://doi.org/10.5065/D69K487J. The ERA-Interim data was produced by ECMWF and was obtained from https://apps. ecmwf.int/datasets/. The station records were provided by the National Meteorological Information Center of the China Meteorological Administration.

Open Access This article is licensed under a Creative Commons Attribution 4.0 International License, which permits use, sharing, adaptation, distribution and reproduction in any medium or format, as long as you give appropriate credit to the original author(s) and the source, provide a link to the Creative Commons licence, and indicate if changes were made. The images or other third party material in this article are included in the article's Creative Commons licence, unless indicated otherwise in a credit line to the material. If material is not included in the article's Creative Commons licence and your intended use is not permitted by statutory regulation or exceeds the permitted use, you will need to obtain permission directly from the copyright holder. To view a copy of this licence, visit http://creativecommons.org/licenses/by/4.0/.

\section{References}

Deng DF, Gao ST, Du XL, Wu WH (2012) A diagnostic study of freezing rain over Guizhou, China, in January 2011. Q J R Meteorol Soc 138:1233-1244. https://doi.org/10.1002/qj.981

Deng D, Gao S, Hu L, Du X, Wang J, Wang C (2015) The impact of Guizhou topography on the distribution of freezing rain in early January 2011. Q J R Meteorol Soc 141:3252-3267. https://doi. org/10.1002/qj.2607

Ding YH, Wang Z, Song YF, Zhang J (2008) Causes of the unprecedented freezing disaster in January 2008 and its possible association with the global warming. Acta Meteorol Sin 66:808-825

Du XL, Lan W (2010) Contrastive analysis on frontal structure of quasi-stationary front in two precipitation processes of YunnanGuizhou. Plateau Meteorol 29:1183-1195 (in Chinese)

Du ZJ, Ding ZY, Zhang SY (2007a) Analysis of atmospheric circulation and structure of Yunnan-Guizhou quasi-stationary front during its evolution. J Trop Meteorol 23:284-292 (in Chinese)

Du ZJ, Xiong F, Su JW (2007b) Some statistical characteristics of Dian-Qian quasi-stationary front during 2001-2003. J Meteorol Res Appl 28:21-23 (in Chinese)

Du XL, Peng F, Wu WH (2010) Distribution and cause on frequent freezing rain zone in Guizhou. Meteorol Mon 36:92-97 (in Chinese)

Du XL, Gao ST, Peng F (2014) Study of the 2011 freezing rain and snow storm in guizhou. Chin J Atmos Sci 38:61-72 ((in Chinese))

Du ZJ, He YL, Xiong F, Deng XH, Shi KY, Peng Q (2015) Analysis on the frontogenesis mechanism of Dian-Qian quasi-stationary front inducing spring rainstorm in Guizhou Province. Plateau Meteorol 34:357-367 (in Chinese)

Duan X, Li Y, Sun XD (2002) The structure of Kunming quasistationary front. Plateau Meteorol 21:205-209 (in Chinese)

Duan X, Duan W, Xing D (2017) A study of objective determination method for the Kunming quasi-stationary frontline. Acta Meteorol Sin 75:811-822 (in Chinese)

Duan X, Duan W, Xing D, Zhang YN (2018a) The relationship between Kunming quasi-stationary front and Yunnan-Guizhou Plateau terrain. Plateau Meteorol 37:137-147 (in Chinese) 
Duan X, Zhang YN, Liang HL (2018b) A comparative analysis of the Kunming quasi-stationary frontal position and frontogenesis function with three different temperature and humidity parameters. Chin J Atmos Sci 42:301-310 (in Chinese)

Egger J, Tao ZY (1992) A note on the dynamics of the quasi-stationary Kunming front. Meteorol Atmos Phys 48:225-229. https:// doi.org/10.1007/BF01029570

Hewson TD (1998) Objective fronts. Meteorol Appl 5:37-65. https:// doi.org/10.1017/S1350482798000553

Hope P, Keay K, Pook M, Catto J, Simmonds I, Mills G et al (2014) A comparison of automated methods of front recognition for climate studies: a case study in southwest Western Australia. Mon Weather Rev 142:343-363. https://doi.org/10.1175/ mwr-d-12-00252.1

Jenkner J, Sprenger M, Schwenk I, Schwierz C, Dierer S, Leuenberger D (2010) Detection and climatology of fronts in a highresolution model reanalysis over the Alps. Meteorol Appl 17:118. https://doi.org/10.1002/met.142

Kašpar M (2003a) Analyses of gust fronts by means of limited area NWP model outputs. Atmos Res 67-68:333-351. https://doi.org/ 10.1016/S0169-8095(03)00066-8

Kašpar M (2003b) Objective frontal analysis techniques applied to extreme/non-extreme precipitation events. Stud Geophys Geod 47:605-631. https://doi.org/10.1023/A:1024767719414

Li Y (1999) Conditional symmetric instability and high-wind and hail accompanying with Kunming quasi-stationary front. J Trop Meteorol 15:3-5 (in Chinese)

Li J, Yu RC (2014) Characteristics of cold season rainfall over the Yungui Plateau. J Appl Meteorol Climatol 53:1750-1759. https:// doi.org/10.1175/jamc-d-13-0285.1

Li DW, Qiao Q, Wei T (2009) Analyses on the freezing rain and snow weather circulation and vertical structure of southern China in early 2008. Plateau Meteorol 28:1140-1148 (in Chinese)

Li J, Yu R, Yuan W, Chen H (2011) Early spring dry spell in the southeastern margin of the Tibetan Plateau. J Meteorol Soc Jpn 89:1-13. https://doi.org/10.2151/jmsj.2011-101

Lu YB, Tan S, Min Y, Hu J, Li HH, Xu YJ, Yang ZY (2019) The analysis of extreme rainstorm process as influenced by the bay of Bengal low and Kunming quasi-stationary front in Yunnan. Adv Meteorol Sci Technol 9:24-31 (in Chinese)

McCann DW, Whistler JP (2001) Problems and solutions for drawing fronts objectively. Meteorol Appl 8:195-203. https://doi.org/10. 1017/S1350482701002079

Qian W, Fu J (2010) Frontal genesis of moisture atmosphere during the early 2008 persistent freezing-rain event in southern China. Sci China Earth Sci 53:454-464. https://doi.org/10.1007/ s11430-009-0101-4

Renard RJ, Clarke LC (1965) Experiments in numerical objective frontal analysis. Mon Weather Rev 93:547-556. https://doi.org/10. 1175/1520-0493(1965)093\%3c0547:Einofa\%3e2.3.Co;2

Sun J, Zhao S (2010) The impacts of multiscale weather systems on freezing rain and snowstorms over southern China. Weather Forecast 25:388-407. https://doi.org/10.1175/2009waf2222253.1
Suo MQ, Ding YH (2016) The discovery and study of Kunming quasistationary front. Adv Meteorol Sci Technol 6:6-16 (in Chinese)

Suo MQ, Ding YH, Lu YB, Tang S, Fan XJ, Li JH (2018) Effects of quasi-stationary fronts in southern China on large-scale freezing rain in winter. Acta Meteorol Sin 76:525-538 (in Chinese)

Tao Y, Duan X, Yao Y, Duan CC, Ren JZ, Chen Y, He H (2018) The climate correlation analysis between the cold wave in Yunnan and Kunming quasi-stationary front. J Catastrophol 33:99-105 (in Chinese)

Wang M, Duan X, Li HH, Fu R (2009) A numerical study of the effect of terrain on Kunming quasi-stationary front (KQSF). Meteorol Mon 35:77-83 (in Chinese)

Wang WP, Yang XQ, Zhang ZQ, Wu ZP (2017) The climatic characteristics and trends of rainy days over China. J Meteorol Sci 37:317-328 (in Chinese)

Xiao YL, Chi ZX, Yan R, Zhai ZY, Liu LJ (2019) Comparative analysis of two torrential rain in the background of quasi-stationary front in Guizhou. Mid-Low Latit Mt Meteorol 43:1-8 (in Chinese)

Yang GM, Mao DY, Kong Q (2009) Analysis of the frontal characteristics of the cryogenic freezing rain and snow weather. Acta Meteorol Sin 67:652-665 (in Chinese)

Yang J, Wang C, Peng F, Li DW (2011) Characteristics of a persistent frontal fog event in low-latitude mountain area. Meteorol Sci Technol 39:445-452 (in Chinese)

Zhang JW, Duan X (2017) Comparative analysis of the typical cold processes influenced by Kunming quasi-stationary front. J Yunnan Univ 39:798-809 (in Chinese)

Zhang YN, Duan X (2018) Structural characteristics of the advance, retreat and maintenance of Kunming quasi-stationary front in January. Plateau Meteorol 37:1375-1387 (in Chinese)

Zhang JH, Zhang WC, Zheng JM, Ma T (2016) Variation of Kunming quasi-stationary front and its effect analysis in winter during 1970-2009. Plateau Meteorol 35:1298-1306 (in Chinese)

Zhao LN, Ma QY, Yang GM, Wang XR, Zhao LQ, Yang XD et al (2008) Disasters and its impact of a severe snow storm and freezing rain over southern China in January 2008. Clim Environ Res 13:556-566 (in Chinese)

Zhao D, Yang RW, Tao Y, Zhang WK, He XC (2019) Objective detection of the Kunming quasi-stationary front. Theoret Appl Climatol 138:1405-1418. https://doi.org/10.1007/s00704-019-02894-w

Zhou BZ, Gu LH, Ding YH, Shao L, Wu ZM, Yang XS et al (2011) The great 2008 Chinese ice storm: its socioeconomic-ecological impact and sustainability lessons learned. Bull Am Meteorol Soc 92:47-60. https://doi.org/10.1175/2010bams2857.1

Publisher's Note Springer Nature remains neutral with regard to jurisdictional claims in published maps and institutional affiliations. 